\title{
Bi-Fe-Sn (Bismuth-Iron-Tin)
}

\section{Raghavan}

Recently, [2010Hua] determined two isothermal sections for this system at 500 and $390{ }^{\circ} \mathrm{C}$, which depict no ternary phases.

\section{Binary Systems}

The Bi-Fe phase diagram shows very little solubility between $\mathrm{Bi}$ and $\mathrm{Fe}$ in the solid state. The $\mathrm{Bi}-\mathrm{Sn}$ phase diagram is a simple eutectic system, with the eutectic at $139{ }^{\circ} \mathrm{C}$ and 57 mass\% $\%$ i. The Fe-Sn system has the following intermediate phases: $\mathrm{Fe}_{5} \mathrm{Sn}_{3}\left(\mathrm{Br}_{2}, \mathrm{Ni}_{2}\right.$ In-type hexagonal), $\mathrm{Fe}_{3} \mathrm{Sn}_{2}$ (rhomboherdral), FeSn (B35, CoSn-type hexagonal) and $\mathrm{FeSn}_{2}\left(C 16, \mathrm{CuAl}_{2}\right.$-type tetragonal). See [Massalski2] for the above binary diagrams.

\section{Ternary Isothermal Sections}

With starting metals of $99.9 \% \mathrm{Bi}, 99.99 \% \mathrm{Fe}$ and $99.9 \%$ Sn, [2010Hua] prepared diffusion couples of

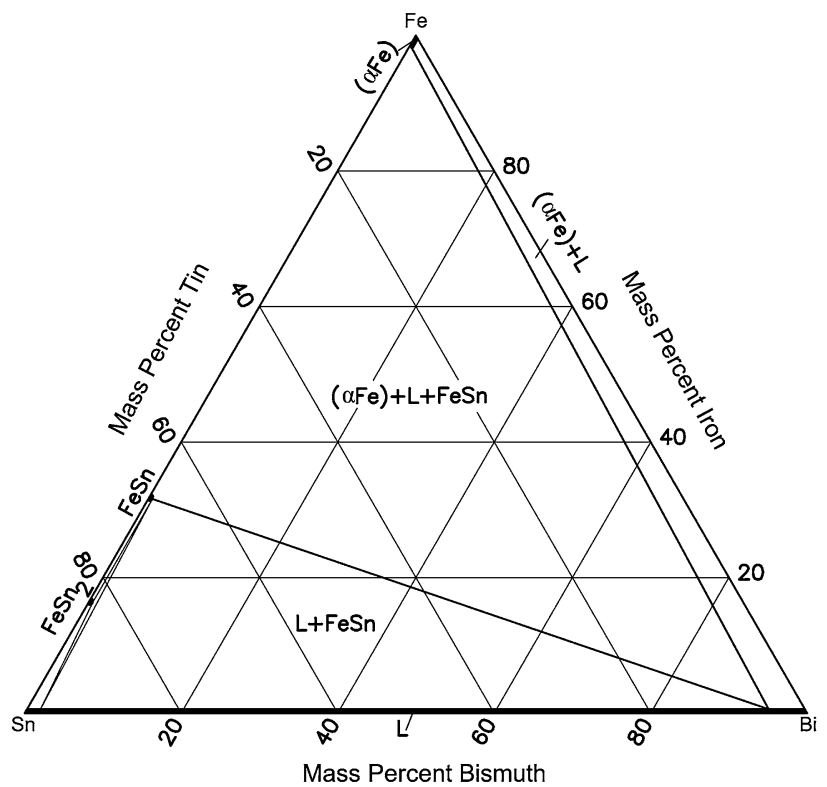

Fig. 1 Bi-Fe-Sn isothermal section at $500^{\circ} \mathrm{C}$ [2010Hua]
$\mathrm{Fe} / \mathrm{Sn}-57$ mass $\% \mathrm{Bi}$, which were annealed at $500{ }^{\circ} \mathrm{C}$ for 3 days and quenched in water. The Sn-Bi alloy was liquid at the annealing temperature. Three ternary alloys were also prepared and given a final anneal at 500 or $390{ }^{\circ} \mathrm{C}$ for 4 months and quenched in water. Using the CALPHAD method, the Fe-Sn phase diagram and three isothermal sections of the ternary system at 500, 395 and $390{ }^{\circ} \mathrm{C}$ were computed by [2010Hua]. The computed isothermal sections at 500 and $390^{\circ} \mathrm{C}$ agree with the experimental results and are shown in Fig. 1 and 2. There is no ternary solubility in the binary phases and no ternary phase was found.

\section{Reference}

2010Hua: Y.C. Huang, W. Gierlotka, and S.W. Chen, Sn-Bi-Fe Thermodynamic Modeling and $\mathrm{Sn}-\mathrm{Bi} / \mathrm{Fe}$ Interfacial Reactions, Intermetallics, 2010, 18, p 984-991

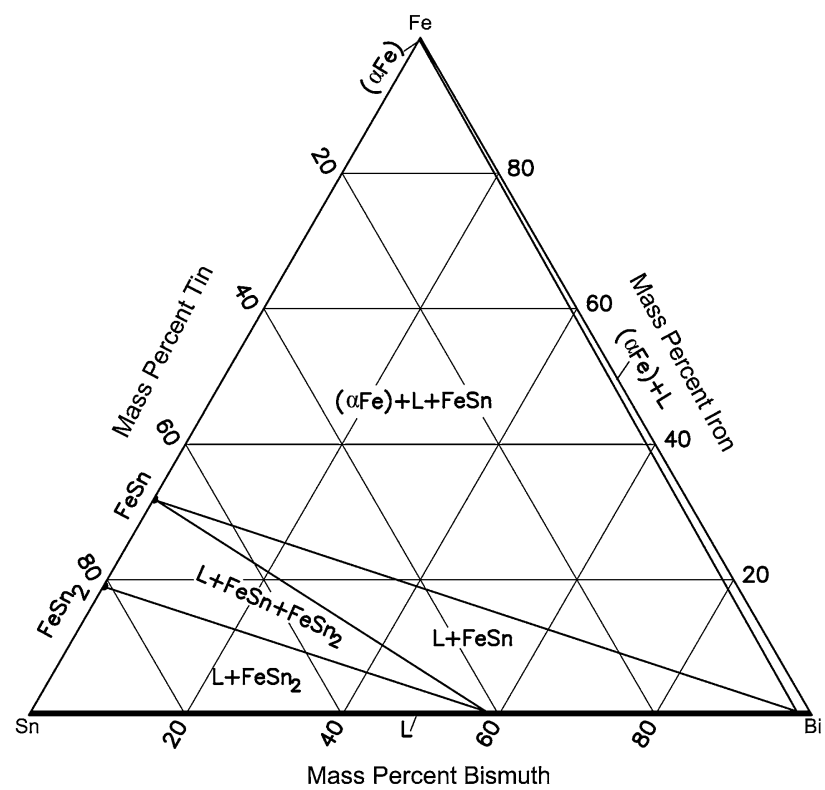

Fig. 2 Bi-Fe-Sn isothermal section at $390^{\circ} \mathrm{C}$ [2010Hua] 